\title{
Effect of Sowing Date and Weather Parameters on Severity of Alternaria Blight on Different Varieties of Brassica juncea
}

\author{
Gagandeep Singh Sohi, Amanpreet Singh, Bahaderjeet Singh* and Mamta Beniwal \\ Department of Plant Pathology, College of Agriculture, Guru Kashi University, Talwandi \\ Sabo-151302, Bathinda (Punjab), India \\ *Corresponding author
}

\begin{tabular}{l} 
K e y w o r d s \\
$\begin{array}{l}\text { Alternaria blight, } \\
\text { Alternaria } \\
\text { brassicae, Disease } \\
\text { severity, Mustard, } \\
\text { Weather parameters }\end{array}$ \\
\hline Article Info \\
$\begin{array}{l}\text { Accepted: } \\
\text { 22 June } 2020 \\
\text { Available Online: } \\
\text { 10 July } 2020\end{array}$ \\
\hline
\end{tabular}

\section{A B S T R A C T}

The oilseed crops especially rapeseed-mustard play a pivotal role in agricultural economy of the world. In Punjab, the area under cultivation of mustard has been decreased due to Brassica crops are extremely susceptible from some major biotic and abiotic stresses. Alternaria blight caused by Alternaria brassicae is one of the most widespread and destructive fungal disease of rapeseed- mustard throughout the world. Field trials were conducted to determine the influence of two sowing dates $\left(22^{\text {nd }}\right.$ October and $05^{\text {th }}$ November) and effect of weather parameters on Alternaria blight intensity during Rabi season 2018-19. In first sowing (D1) 26.16 percent and second sowing (D2) 45.39 highest percent disease intensity (PDI) was recorded by PBR-97 and Giriraj was comparatively less disease severity in both sowing dates (D1-4.79, D2-10.65). Overall mean percent of disease severity was 17.73 and 30.35 at D1 and D2 respectively. Disease severity was increase with delay in date of sowing. Weather factors also play an important role in disease flourish. The maximum temperature $\left(17.9-31.8^{\circ} \mathrm{C}\right)$ and minimum temperature $\left(2.2-15.2^{\circ} \mathrm{C}\right)$ positively correlated and minimum relative humidity $(30.6-63.7 \%)$, maximum relative humidity $(74.1-92.6 \%)$ and rainfall had significant negative correlated with disease severity.

\section{Introduction}

In India, rapeseed-mustard is the $2^{\text {nd }}$ important edible oil crop after groundnut and $27.8 \%$ share of oil production. Mustard occupies 6.421 million hectares area 6.33 million tonnes production in India (Anonymous, 2017-2018). In Punjab, rapeseed-mustard were grown on 31.7 thousand hectares during 2016-17 with production of 44.8 thousand tonnes and an average yield of 14.13 quintals per hectare (Anonymous, 2018-19).

Brassica spp. is extremely susceptible from some major biotic (diseases and pests) and abiotic stresses (environment factors). Major abiotic stress namely; Temperature, humidity, 
rainfall and sunshine are playing vital role in the development of the disease. More than thirty diseases are known to occur on Brassica crop in India (Saharan et al., 2005). Some major and common disease of rapeseedmustard in India are Leaf spot and blight $(A$. brassicae, A. brassicicola, A. altetrnata), White rust (Albugo candida), Sclerotinia rot (Sclerotinia sclerotiorum), Downy mildew (Peronospora brassicae), Black rot (Xanthomonas compestris pv. Campestris) and Mosaic, which influence the quality and quantity of seed (Saha and Singh, 1988; Kolte, 2005; Mehta et al., 2005). Alternaria blight is one of the major and important fungus disease of rapeseed-mustard. Alternaria blight of mustard caused by $A$. brassicae and $A$. brassicicola are found everywhere in rapeseed-mustard cropping areas and decrease 15-71 percent in productivity, 14-36 percent in oil content (Meena et al., 2010).

Besides losses in oil content and crop yield, also harmful effect on seed quality causing reduction in seed size and leading to discoloration (Prasad and Lallu, 2006). Hence, the most cost effective and ecofriendly mean of managing the Alternaria blight of rapeseed-mustard would be use resistant and tolerance varieties. However, the information in regard of resistant source is not available, but some sort of tolerance may be available (Shah et al., 2005; Rajendra et al., 2002). Some other points, date of sowing or planting are important factors for severity of crop disease. Adjust the sowing time of Indian mustard is basic techniques to reduce the Alternaria blight incidence (Ayub, 2001; Mian and Akanda, 1989). Khatun et al., (2011) conducted a field trail to find out the effect of sowing date on disease severity (Alternaria blight) of mustard. They describe that, disease percentage on leaf and silique and spot per part were found lower under $21^{\text {st }}$ October sowing. Dang et al., (1995) research the relationship of weather conditions with Alternaria blight on rapeseed-mustard. Suitable weather conditions for development of A. brassicae are $16.3^{\circ} \mathrm{C}$ to $25.7^{\circ} \mathrm{C}$ temperature and $2.5-6.0 \mathrm{~km} / \mathrm{hrs}$ wind velocity. Temperature, relative humidity and sunshine hours are playing major and important role for development of $A$. brassicae on rapeseedmustard. The result of weather factors on $A$. brassicae had a positive correlation between PDI and temperature, while it was negatively correlated with rainfall and relative humidity (Bal and Kumar, 2014). The existing fungicidal control measures are neither economical nor environmental friendly; therefore an economically and eco-friendly way to manage the disease effectively is required. Identification of resistant varieties and alteration of sowing time can be a better agronomic practice to control the diseases; in this regard we attempted four verities and two different sowing dates to evaluate the effect of weather parameters and sowing dates on the severity of Alternaria blight of Indian mustard.

In order to determine the most effective dates of sowing that permits high or low level of

\section{Materials and Methods}

The experiment was conducted at Guru Kashi University, Talwandi Sabo (Bathinda) during Rabi crop season 2018-2019, in a split plot design with three replications and different four varieties of $B$. juncea (PBR-97, Varuna, Giriraj and Parasmani 2), were sown on two sowing dates [October 22 $2^{\text {nd }}$ (D1) and November $05^{\text {th }}$ (D2)] standard spacing and use recommended doses of $\mathrm{N}, \mathrm{P}$ and $\mathrm{K}$ fertilizers in natural conditions. Data was recorded from the initial date of appearance of Alternaria blight symptoms on leaves of mustard were scrutinized. Observe data once in 7 days for recorded the percent disease intensity (PDI). The meteorological data was 
obtained from Punjab Agriculture UniversityRegional Research Station, Bathinda-151001 (Punjab). Selected five randomly plants in each plot and were tagged for taking observations for disease component. To calculated PDI, use 0 to 9 disease rating scale developed by Mayee and Datar, (1986) (Table 1 and Fig.1). Percent disease intensity was calculated by the formula as below:

Percent disease intensity $(\mathrm{PDI})=$

Sum of individual rating scale

Noof disease Plants observed X Maximum disease

\section{Results and Discussion}

Effect of sowing dates and varieties on Alternaria blight intensity

At GKU field during Rabi season (2018-19); PBR-97, T-59 (Varuna), Giriraj and Parasmani-2 significantly highest overall mean of disease intensity 45.39, 29.37, 10.65 and 35.99 percent recorded in $2^{\text {nd }}$ sowing and 26.16, 14.86, 4.79 and 23.89 percent recorded in $1^{\text {st }}$ sowing respectively. Overall mean of disease severity is 17.73 and 30.35 in D1 and D2 respectively. Disease severity has increase with delay in date of sowing. These results also support the finding of Mian and Akanda, (1989) who have recommended early sowing for minimum damage of crop from Alternaria leaf blight disease. Khatun et al., (2011) reported that delay in sowing increase the infection of Alternaria blight and reduction in seed yield.

Results expose that in all four $B$. juncea varieties, Alternaria blight intensity varied significantly with the sowing dates and has also found to be increased steadily with age of the crop. PBR-97 recorded maximum mean of disease intensity of 26.16 and 45.39 percent in the crop sown on D1 and D2 respectively. Giriraj recorded minimum mean of disease intensity 4.79 and 10.65 percent in the crop sown on D1 (Highly resistant) and D2 (Moderately resistant) respectively. During this season disease intensity on all the Indian mustard varieties, from its first appearance increased steadily with age of the crop and the rate of disease intensity was maximum in susceptible cv. PBR-97 than that of Parasmani-2, T-59 (Varuna) and Giriraj. Parasmani-2 also shows higher disease intensity 23.89 and 35.99 in D1 and D2 respectively than T-59 (Varuna) and Giriraj. Interaction effects $(\mathrm{D} \times \mathrm{V})$ in respect of disease severity at various intervals has found significant. The effect of sowing dates and varieties on Alternaria blight intensity is summarized in Table 2 and Fig. 2.

\section{Effect of Weather parameters on Alternaria blight intensity}

The different weather parameters viz., temperature (maximum and minimum), relative humidity (maximum and minimum) and rainfall (mm) affecting epidemic development under field conditions were considered. The progress of Alternaria blight was studied on four varieties namely; PBR97, T-59 (Varuna), Giriraj and Paramsani-2 in terms of increase in number of spots. Temporal progress was measured at seven days interval starting from the appearance of the disease symptoms during 2018-19 crop seasons.

The maximum number of spots has observed on PBR-97 followed by Parasmani-2, T-59 (Varuna) and Giriraj. Temperature (maximum and minimum) showed significant positive correlation, while relative humidity and rainfall has significant negative correlation with the varieties sown on $22^{\text {nd }}$ October and $05^{\text {th }}$ November. Correlation analysis of disease intensity with weather factors indicated that maximum temperature (17.9$31.8^{\circ} \mathrm{C}$ ) and minimum temperature (2.2- 
$15.2^{\circ} \mathrm{C}$ ) has a significant positive correlation with disease intensity, While minimum relative humidity (30.6-63.7\%), maximum relative humidity (74.1-92.6\%) and rainfall has significant negative correlation (Table 3 and Fig. 3). These results are in agreement with the earlier studies like Bal and Kumar, (2014) testified the result of weather factors (temperature, relative humidity and rainfall) on Alternaria leaf blight of mustard had a positive correlation between the disease intensity and temperature, it was negatively correlated with rainfall and relative humidity. The inference from the current study is that $2^{\text {nd }}$ fortnight of October is suitable for the sowing of mustard.

Table.1 Alternaria blight disease rating scale

\begin{tabular}{|c|c|c|}
\hline Rating Scale & Disease Intensity Per cent & Disease reaction \\
\hline 0 & 0 & Immune (I) \\
\hline 1 & Less than 5\% & Highly resistant (HR) \\
\hline 3 & $5-10 \%$ & Resistant (R) \\
\hline 5 & $11-25 \%$ & Moderately resistant (MR) \\
\hline 7 & $26-50 \%$ & Susceptible (S) \\
\hline 9 & More than 50\% & Highly susceptible (HS) \\
\hline
\end{tabular}

Table.2 Effect of sowing dates and Indian mustard varieties on Alternaria blight intensity during Rabi, 2018-2019

\begin{tabular}{|c|c|c|c|}
\hline \multirow{3}{*}{ Sowing Dates } & \multirow{3}{*}{ Varieties } & \multicolumn{2}{|c|}{ Per cent disease intensity (Severity) } \\
\hline & & \multicolumn{2}{|c|}{ Plant } \\
\hline & & PDI & Disease Reaction \\
\hline \multirow{4}{*}{$\begin{array}{c}\text { D1 } \\
(22.10 .2018)\end{array}$} & PBR-97 & 26.16 & S \\
\hline & T-59 (Varuna) & 14.86 & MR \\
\hline & Giriraj & 4.79 & HR \\
\hline & Parasmani-2 & 23.89 & MR \\
\hline Overall mean & & 17.43 & \\
\hline \multirow{4}{*}{$\begin{array}{c}\text { D2 } \\
(05.11 .2018)\end{array}$} & PBR-97 & 45.39 & $\mathbf{S}$ \\
\hline & T-59 (Varuna) & 29.37 & $S$ \\
\hline & Giriraj & 10.65 & MR \\
\hline & Parasmani-2 & 35.99 & $\mathrm{~S}$ \\
\hline Overall mean & & 30.35 & \\
\hline \multirow[t]{3}{*}{ C.D. $(P=0.05)$} & $\mathrm{D}$ & \multicolumn{2}{|c|}{2.88} \\
\hline & V & \multicolumn{2}{|c|}{2.32} \\
\hline & $\mathrm{D} \times \mathrm{V}$ & \multicolumn{2}{|c|}{3.804} \\
\hline
\end{tabular}

D1- First sowing

D2- Second sowing 
Table.3 Correlation-coefficient between weather parameters and Alternaria blight intensity on Indian mustard varieties during Rabi, 2018-19

\begin{tabular}{|c|c|c|c|c|c|c|}
\hline \multirow[t]{2}{*}{ Variety } & \multirow{2}{*}{$\begin{array}{l}\text { Date of } \\
\text { sowing }\end{array}$} & \multicolumn{5}{|c|}{ Correlation Coefficient (r) Weather factor } \\
\hline & & $\mathbf{X} 1$ & $\mathbf{X} 2$ & $\mathbf{X 3}$ & $\mathbf{X} 4$ & X5 \\
\hline \multirow[t]{2}{*}{ PBR 97} & D1 & 0.28 & -0.12 & -0.38 & -0.258 & -0.236 \\
\hline & D2 & -0.189 & 0.416 & 0.241 & -0.499 & -0.484 \\
\hline \multirow[t]{2}{*}{ Giriraj } & D1 & 0.342 & 0.094 & -0.392 & -0.254 & -0.290 \\
\hline & D2 & 0.309 & -0.134 & -0.119 & -0.457 & -0.351 \\
\hline \multirow[t]{2}{*}{ T-59 } & D1 & -.0348 & 0.219 & 0.039 & 0.142 & -0.047 \\
\hline & D2 & 0.417 & 0.718 & -0.239 & -0.009 & 0.356 \\
\hline \multirow[t]{2}{*}{ Parasmani 2} & D1 & 0.456 & 0.242 & -0.418 & -0.231 & -0.238 \\
\hline & D2 & 0.014 & -0.270 & 0.158 & -0.512 & -0.437 \\
\hline \multicolumn{2}{|c|}{ Overall Mean } & 0.199 & 0.146 & -0.174 & -0.312 & -0.216 \\
\hline
\end{tabular}

Fig.1 Disease rating scale for Alternaria blight in mustard

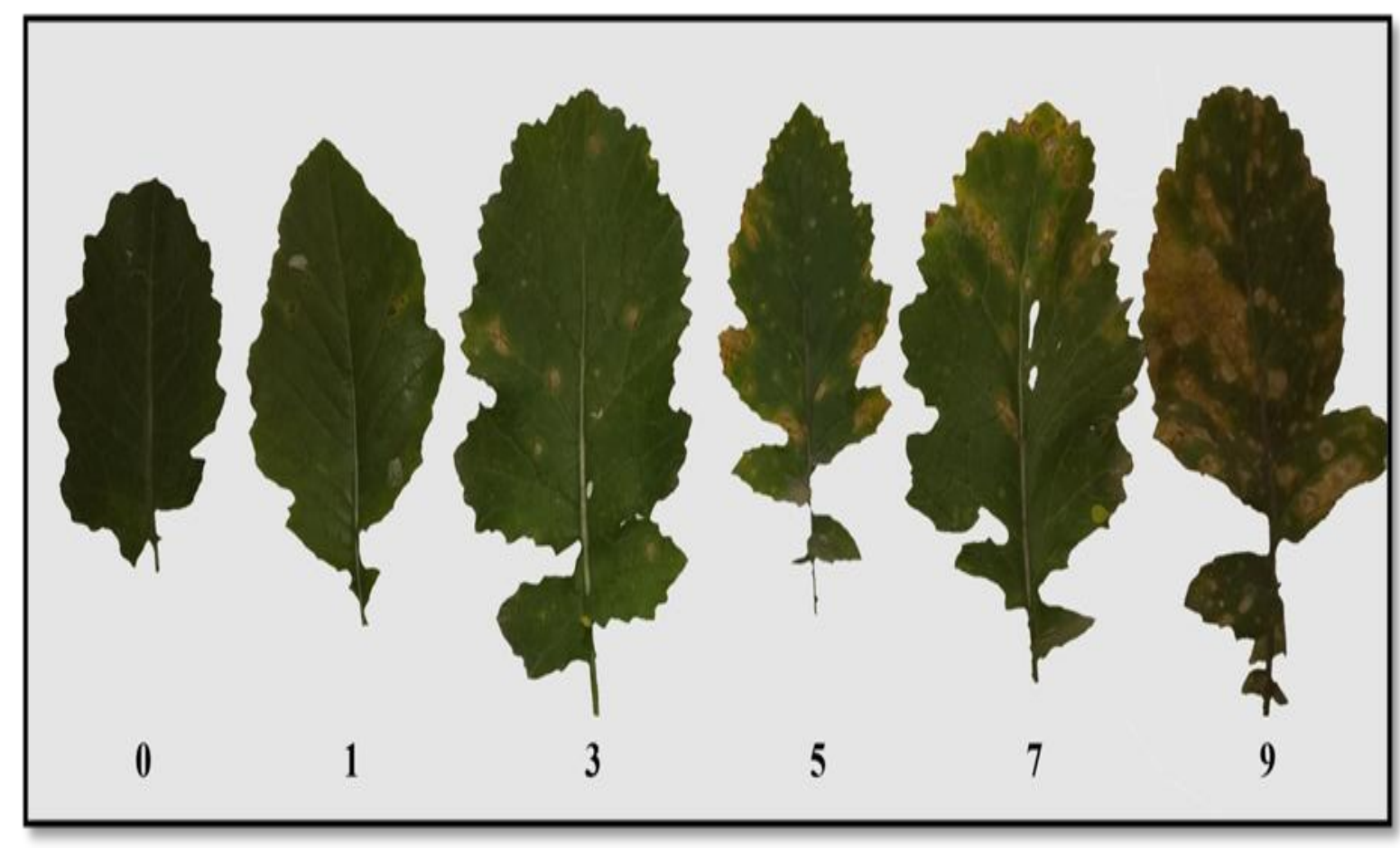


Fig.2 Effect of sowing dates and Indian mustard varieties on Alternaria blight intensity during Rabi, 2018-2019

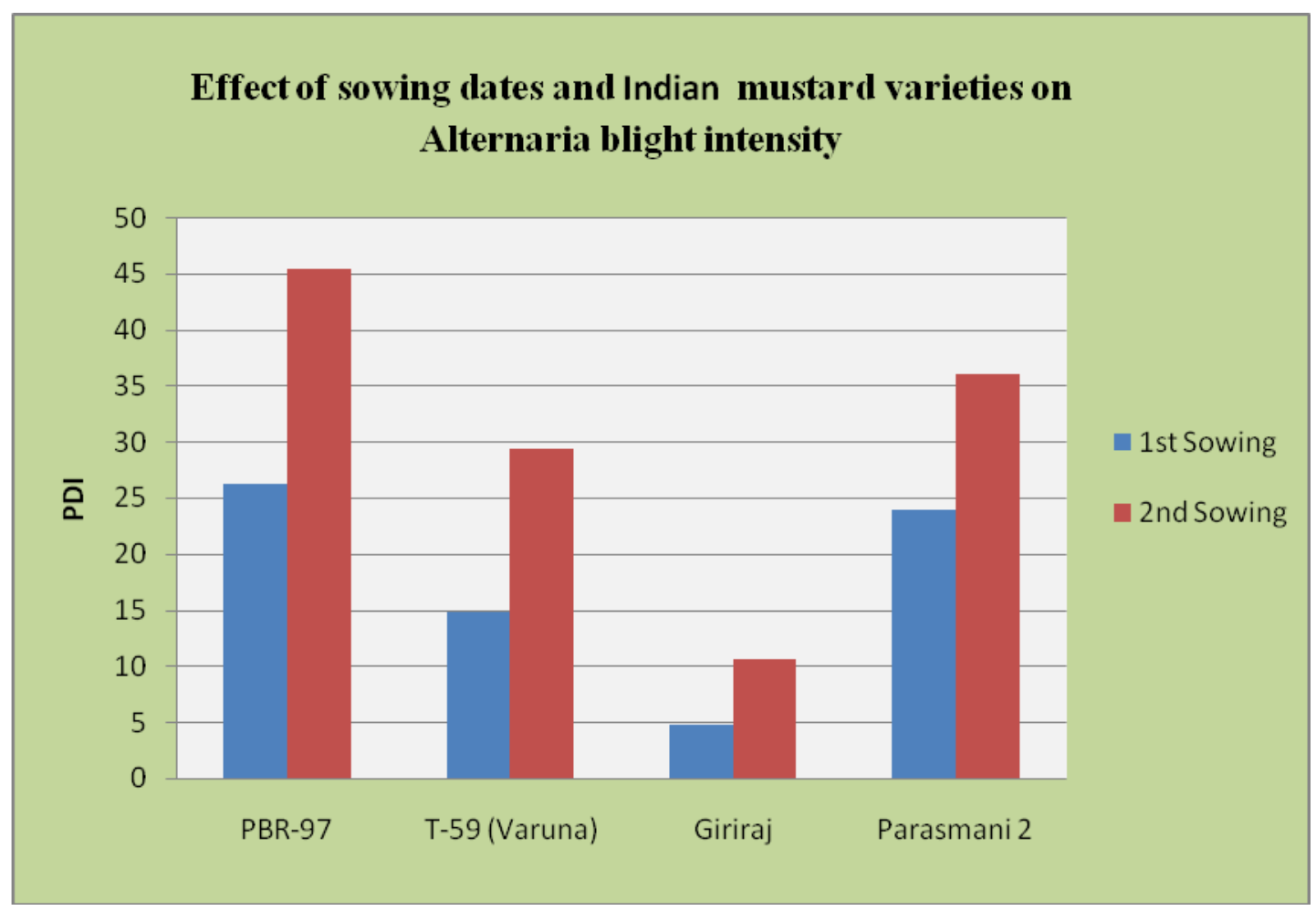

Fig.3 Correlation-coefficient between weather parameters and Alternaria blight intensity on Indian mustard varieties during Rabi, 2018-19

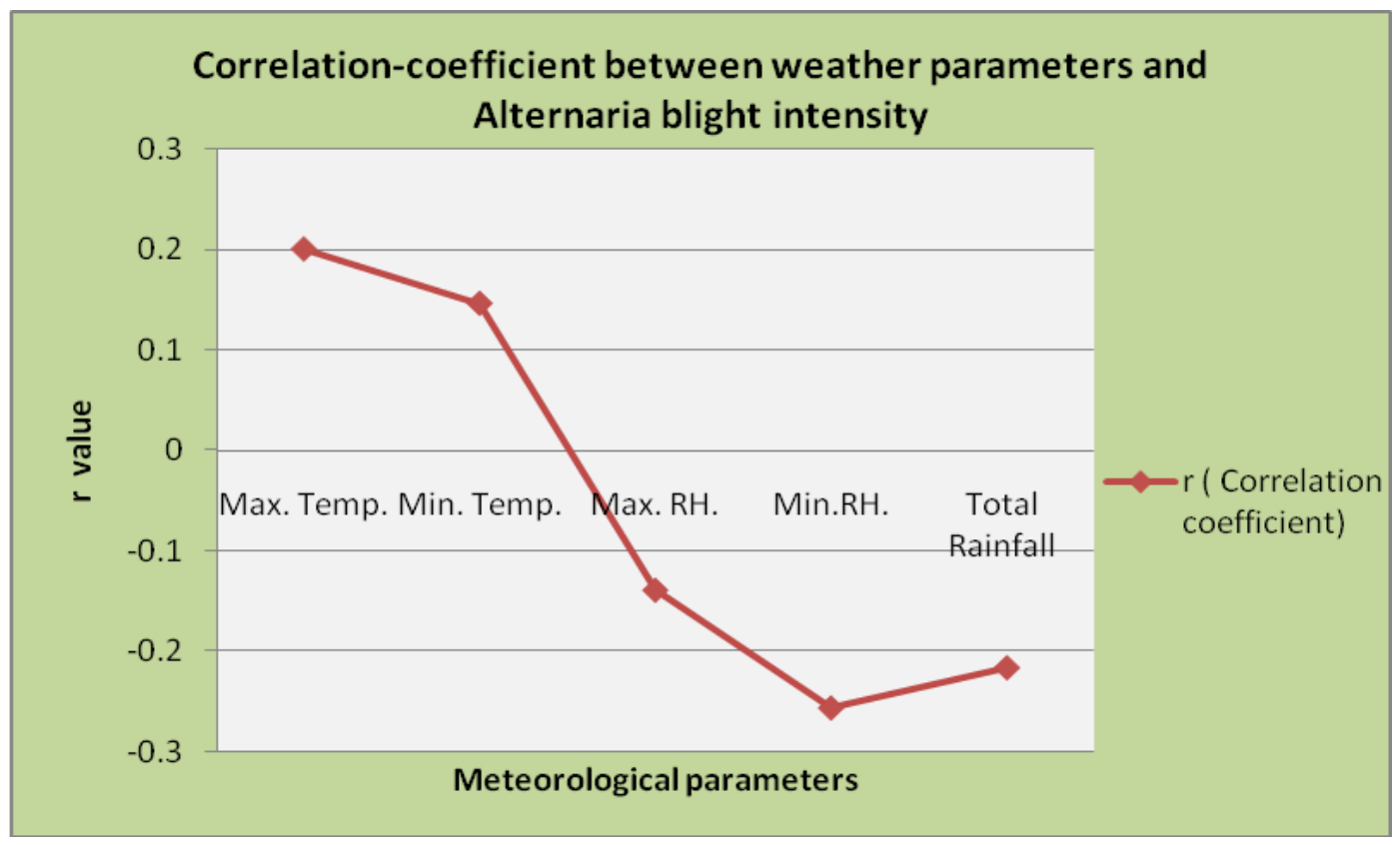


In the present investigation, the data for the Rabi season (2018-19) revealed that is periodical increase in the disease severity with delay in date of sowing. Overall mean of PDI is 17.43 and 30.35 at D1 and D2 respectively. Hence, it means disease severity increase with delay in date of sowing and $2^{\text {nd }}$ fortnight of October is suitable for the sowing of mustard and control disease severity. Similar findings have also been advocated by Mian and Akanda (1989); Khatun et al., (2011) and Kolte et al., (1987). PBR-97 recorded maximum mean disease intensity 26.16 and 45.39 percent in the crop sown on D1 and D2 respectively and Giriraj recorded low mean disease intensity 4.79 and 10.65 percent in the crop sown on D1 and D2 respectively. Giriraj variety of $B$. juncea is highly resistant against $A$. brassicae, while PBR-97 and Parasmani-2 are more susceptible from A. brassicae.

Suitable weather factors viz., temperature, relative humidity and rainfall are playing an important role in the progression of $A$. brassicae. Maximum and minimum temperature showed significant and positive correlation with Alternaria blight while relative humidity (maximum and minimum) and rainfall has significant negative correlation. These results are in agreement with the earlier studies by Bal and Kumar, (2014); Awasthi and Kolte, (1994).

\section{References}

Ajub, A. (2001). Studies on control of Alternaria leaf blight of cauliflower seed crop. Ph.D. Thesis. Department of Plant Pathology. Bangabandhu Sheikh Mujibur rahman Agriculture University, Salna, Gazipur, Banglasesh, pp 88.

Anonymous (2017-18). Directorate of Economics and Statistics, Department of Agriculture and Cooperation, Delhi, pp 10-12.
Anonymous (2018-19). Package of Practices of cultivation for Rabi crops. Punjab Agriculture University, Ludhiana, 35: 19.

Awasthi, R.P. and Kolte, S.J. (1994). Epidemiological factors in relation to development \& prediction of Alternaria blight of rapeseed-mustard. Indian Phytopathology, 38: 721-726.

Bal, R.S. and Kumar, A. (2014). Studies on the epidemiology of white rust and Alternaria leaf blight and their effect on the yield of Indian mustard. African Journal of Agricultural Research, 9(2): 302-306

Dang, J.K., Kaushik, C.D. and Sangwan, M.S. (1995). Quantitative relationship between Alternaria leaf blight of rapeseed-mustard \& weather variables. Indian Journal of Mycology and Plant Pathology, 25 (3): 184-188.

Khatun, F., Alam, M.S., Hossain, M.A., Malaker, P.K. and Rashid, M.H. (2011). Effect of sowing dates and varieties on the severity of Alternaria blight of the mustard. Bangladesh Journal of Agricultural Research, 36 (4): 583-594.

Kolte, S.J. (2005). Tackling fungal diseases of oil seed Brassicas in India. Brassica, 7 (1/2): 7-13.

Kolte, S.J., Awasthi, R.P. and Vishwanath (1987) Assessment of yield losses due to Alternaria blight in rapeseed and mustard. Indian Phytopathology, 40: 209-211

Mayee, C.D. and Datar, V.V. (1986). Phytopathomethory. Marathwada Agric. Univ. Parbhani (M.S.) India, pp 100104.

Meena, P.D., Awasthi, R.P., Chattopadhyay, C., Kolte, S.J. and Kumar, A. (2010). Alternaria blight: a chronic disease in rapeseed-mustard. Journal of Oilseed Brassica, 1(1): 1-11.

Mehta, N., Sangwan, M.S. and Saharan, G.S. (2005). Fungal diseases of rapeseed 
mustard. Diseases of Oil Seed Crops, pp 15-86.

Mian, I.H. and Akanda, A.M. (1989). Effect of sowing time, irrigation, soil moisture and nutrient status on Alternaria blight of mustard. Bangladesh Journal of Plant Pathology, 5: 77- 80.

Prasad, R. and Lallu, P. (2006). Management of Alternaria blight of mustard with combination of chemicals and botanicals. Annual Review of Plant Protection Science, 14: 400-403.

Rajendra, P.S., Deepa, S., Mahak; Prasad, R., Saxena, D. and Singh, M. (2002). Studies on resistance of different rapeseed and mustard cultures to Alternaria blight. Indian Annals of Plant protection Science, 10(2): 398-399.
Saha, L.R. and Singh, H.B. (1988). Diseases of rapeseed and mustard and their management. Review of Tropical Plant Pathology, 5:47-77

Saharan, G.S., Mehta, N. and Sangwan, M.S. (2005). Fungal diseases of rapeseed mustard. In: Sangwan, M. S., Saharan, G. S., Mehta, N. (eds) Diseases of oilseed crops. New Delhi: Indus Publishing Company, pp 15-86.

Shah, S.A., Iftikhar, A., Rahmkan, K. and Mumtaz, A. (2005). 'NIFA-mustard canola' first mutant variety of oilseed mustard (Brassica juncea COSS \& CZERN) in Pakistan. Mutation Breeding-Newsletter and Reviews, 1: 22-23.

\section{How to cite this article:}

Gagandeep Singh Sohi, Amanpreet Singh, Bahaderjeet Singh and Mamta Beniwal. 2020. Effect of Sowing Date and Weather Parameters on Severity of Alternaria Blight on Different Varieties of Brassica juncea. Int.J.Curr.Microbiol.App.Sci. 9(07): 3732-3739. doi: https://doi.org/10.20546/ijcmas.2020.907.437 